\title{
Monographische Beiträge zur Käferfauna von Central-Aınerika.
}

\section{Rutelidae :}

Epectinaspis und Strigoderma.

Von

A. Fr. Nonfried in Rakonitz.

Die mir letzter Zeit tubertragene Durchsicht und Determination der im Besitze des Museum Rothschild in Tring befindlichen Ruteliden, zumeist aus der Ausbeute Boucard's und Sallé's von Centralamerika stammend - ferner der Umstand, als ich durch vortheilhafte Verbindung mit bisher entomologisch unexploirten Provinzen von Central-Honduras viel Material bekam, das mir beim Vergleichen der Spezies vorzügliche Dienste leistete - bewog mich, die Ruteliden von Central-Amerika monographisch zu bearbeiten. In erster Linie habe ich die Epectinaspis und Strigoderma in Angriff genommen; später werden die anderen Gattungen folgen.

Bei Strigoderma habe ich die in dem vorzüglichsten descriptiven Werke über die Col.-Fauna Central-Amerikas - nämlich in Bates Biologia Centrali Americana - aufgestellte Regel beibehalten, nämlich die Eintheilung dieser Gattung in Gruppen, die nach der Anzahl der zwischen der Nath und den Schulterbuckeln befindlichen Rippenstreifen geordnet sind - natürlich mit Berücksichtigung anderer Unterscheidungsmerkmale.

Endlich sei noch der Zuvorkommenheit dankend erwähnt, mit welcher Dr. C. Jordan mir die Ruteliden des Rothschild'schen Museums zur Verfugnng stellte; denn die Mehrzahl der neuen Arten und Varietäten war darin enthalten.

\section{Epectinaspis Blanch.}

(Kopf länglich-quadratisch, dicht punktirt; Clypeus vorne stumpf abgerundet, mit scharf aufgebogenem Vorderrande, flach. Thorax kreisrund, hoch gewölbt, dicht punktirt, kurz anliegend behaart. 
Schildchen breit. Flügeldecken fast flach gewölbt, regelmåssig gefurcht; Furchen ttef, aus groben Punkten bestehend. Randschwiele geschweift, verdickt, bei $\&$ ganz fehlend. Beine kurz, gedrungen, bei $q$ schmächtiger, der Mesosternalfortsatz nicht vorspringend, ganz schmal. Das Haarkleid sperrig, borstig.)

A. Arten mit metallisch glänzender Oberfläche.

Type: Epect. mexicana Burm.

1. Dunkelgrün, metallisch glänzend. Clypeus kupfrig schillernd, Fühler braun, der Fächer bei $\sigma^{7}$ lang, bei $\$$ kürzer. Thorax gelb, erzglänzend, oben in der Mitte eine dunkelgrüne, konische Makel, deren Spitze das Schildchen erreicht. Flügeldecken mit 9 Punktstreifen, entweder gelb, oder aber ganz schwarz, schwach bronzeglänzend. Pygidium dicht ehagrinirt Unten braun mit Erzglanz, die Hinterschenkel oben gelblich, Tarsen dunkler.

Länge 7-9 mm. Mexiko: mexicana Burm.

Burm. Handb. IV, pag. 241.

2. Röthlich oder grün, metallisch glänzend; Kopf, Thorax und Schildchen unbehaart, erzgrün, Unterseite ebenso gefärbt, aber schütter greis behaart. Kopf in der Mitte vertieft; Clypeus bei $\sigma^{7}$ gross, scharf umrandet, bei of weniger quadratisch, auch kleiner und schwach umrandet. Flügeldecken entweder schwärzlichgrün, oder gelbbraun, oder endlich kastanienbraun, alle drei entweder braun oder roth gemakelt. Die zweite und siebente Rippenfurche an der Basis zerflossen und grob punktirt. Pygidium dicht verworren punktirt, lang behaart.

Iänge $8-10 \mathrm{~mm}$. Aus Guatemala: chalconota Bates. Bates, Biol. Centr. Amer. pag. 407.

3!. Licht gelbbraun, kurz greis behaart. Kopf purpurbraun, unbehaart; Futhler braun. Thorax feinst punktirt, beim Scheitel eine dreieckige dunkelgrüne Makel und beiderseits beim Seitenrand ein ebenso gefärbter Flecken. Schildchen grün. Flügeldecken gelbbraun, die Randschwiele am Anfang breit, verdickt. Pygidium und Unterseite schwarzgrün, dicht punktirt, schütter behaart; Schenkel und Schienen gelbbraun, erzglänzend, die Schienenenden und die Tarsen rothbraun.

Länge $9-11 \mathrm{~mm}$. Aus Mexiko:

Boucardi n. sp.

3". Wie die vorhergehende Art gestaltet und gefärbt, nur mit dichterem Haarkleid versehen, auch fehlt der Thoraxflecken gänzlich; unterseits gelblich-roth, die Brust grün, die Schienenenden ohne rothbraunen Anflug.

Länge $12 \mathrm{~mm}$. Aus Mexilko: Bouc. var. unicolor n. v. 
B. Arten ohne Metallglanz oberseits.

Type: Epect. opacicollis Bat.

4. Lang gestreckt, glänzend licht gelbbraun. Kopf dunkel braunroth; Funhler schmutzig gelb. Thorax unbehaart, oben mit einer grossen runden, schwarzen Makel. Flügeldecken schmal, die Nath und die Ränder des dicht punktirten Schildchens schwarzbraun. Pygidium schütter behaart. Tarsen dunkel gelbbraun.

Iänge $12 \mathrm{~mm}$. Aus Central-Honduras: hondurae Nonfr. Berl. entom. Zeit. 1891, pag. 231.

5. Kopf dicht punktirt, schwarz, matt; die Fühler braun, der sehr lange Fühlerfächer schwarzbraun. Thorax gelbbraun, in der Mitte eine breite schwarze Makel, die oft so breit wird, dass nur ein schmaler gelber Rand erübrigt. Schildchen zerstreut punktirt, glänzend. Flügeldecken entweder braungelb, die Nath, ein quadratischer Flecken dicht am Schildchen und zwei Längsstreifen neben den Seitenrändern dann schwarz oder sind sie ganz schwarz - endlich können sie auch röthlichgelb sein, in beiden letzten Fällen etwas kupferig schimmernd, was dann auch beim Kopf und Thorax der Fall ist. Die beiden letzt angeführten Farbenvarietäten kommen ausschliesslich aus Guatemala. Pygidium lang behaart. Unten glänzend rothbraun oder schwarz, die Füsse rothbraun.

Länge $8-11 \mathrm{~mm}$. Aus Mexiko und Guatemala:

pictipennis Bates.

Bates 1. c. pag. 250 , Tf. 14, fig. 4 .

6. Kopf schwarzgrün, Scheitel abstehend behaart. Fühler dunkelbraun. Thorax schmutzig gelb, feinst punktirt, am Scheitel eine braune nierenförmige Makel. Schildchen grünlich schimmernd, behaart. Flügeldecken mit unregelmässigen Furchen, die zweite und achte vorne sehr erweitert, die Randschwiele flach, breit, in der Mitte verdickt, egal gelbbraun. Pygidium stark convex, greis behaart. Unten schwärzlich, dicht gestrichelt, schütter behaart; Füsse schaalgelb mit Erzglanz; Tarsen rothbraun.

Länge $8-11 \mathrm{~mm}$. Aus Mexiko:

Bates l. c. pag. 251 , Tf. 14 , fig. 5 .

Mattschwarz mit Frzschimmer. Kopf und Thorax abstehend behaart, Fühler schwarz. Schildchen zerstreut punktirt. Flügeldecken kastanienbraun, grob und verworren punktirt gestreift, bei den Schulterbuckeln eingedrückt, die Randschwiele nach hinten breiter, jedoch nicht verdickt. Pygidium chagrinirt, ebenfalls braun. Unten spärlich 
behaart, schwach grunlich schimmernd; Füsse mit schütteren groben, länglichen Punkten.

Länge $10 \mathrm{~mm}$. Aus Britisch-Honduras: ambigens Bates. Bates l. c. pag. 252.

64. Glänzend gelbbraun $\left(0^{\prime}\right)$ oder schwarz (우). Kopf äusserst dicht körnig, schwarzbraun; Clypeus gelbbraun, Fühler dunkelbraun. Thorax fein gekielt, an den Rändern zerstreut punktirt, oben fast glatt, kurz behaart, gelbbraun; $\left(\sigma^{\prime}\right)$ vor dem Scheitel eine braune dreieckige Makel - oder bei $ᄋ$ ganz schwarz. Schildchen braun oder schwarz, Flügeldecken seicht gefurcht, bei den Schulterbuckeln ziemlich tief eingedruckt, die Randschwiele an der Basis breiter und verdickt. gelbbraun oder schwarz, glänzend. Pygidium gleich gefärbt, lang behaart. Unten sperrig punktirt, greis behaart; Tarsen dunkler $\left(\sigma^{\circ}\right)$, Klauen lang, robust, das erste Tarsenglied bei $\sigma^{7}$ zangenförmig gestaltet.

Länge 8-11 mm. Aus Panama:

Bates 1. c. pag. 251, Tf. 14, fig. 6 .

chelifera Bates.

7. Robust, licht röthlichbraun. Kopf, Thorax und Schildchen schwarz, Flügeldecken rothbraun. Kopf dicht punktirt, unbehaart; Fuhler mattschwarz. Thorax selr dicht punktirt und kurz fein behaart. Schildchen höchst fein punktirt, ohne Haare. Flügeldecken flach punktirt-gestreift, die Gegend um das Schildchen glatt, mit einzelnen groben Punkten; Schulterbuckeln hoch, fein punktirt, die Randschwiele und die Nath dunkler braun gefärbt. Pygidium und Unterseite glänzend schwarz, spärlich punktirt, schüttcr behaart.

Länge $8-11 \mathrm{~mm}$. Aus Mexiko und Gtatemala:

Moreletiana Blanch.

Blanchard, Cat. Coll. Ent. 1850, pag. 179.

7. Wie die vorige Art gestaltet, jedoch ganz schwarz, mässig glänzend. Kopf sehr dicht punktirt und wie die Fühler schwarz; ebenso der Thorax, der abstehend gelbbraun behaart erscheint. Schildchen unbehaart, die Mitte chagrinirt, die Ränder glatt, glänzend. Flügeldecken flach punktirt-gestreift, entweder gänzlich schwarz oder gelbbraun gefleckt, und zwar befindet sich letzten Falles je ein Flecken neben dem Schildchen, je einer in der Mitte dicht an der Nath, je ein weiterer ihm gegentiber am Rande, endlich je einer am Endbuckel. Pygidium fein chagrinirt, spärlich behaart. Unten glänzend, flach punktirt, schütter behaart.

Länge 9-10 mm. Aus Guatemala: Morel. var. tristis n. v.

Bemerkung: Die im Gemminger-Harold'schen Cataloge bei Epectinaspis angeführten Arten Castor Newm. und Pollux Newm. 
gehören ihrer Körperbildung nach richtig zu der Strigoder'ma, wohin sie auch Bates einreihte. Pollux ist vom Castor sehr wenig verschieden und als eine von der Stammart wenig abweichende Farbenvarietät anzusehen.

\section{Strigoderma Burm.}

(Länglich-elliptisch, gestreckt; Kopf subquadratisch, dicht gekörnt, unbehaart; Clypeus kurz, vorne abgerundet, mässig erhaben umrandet, von der Stirn durch eine schwache Querfurche gesondert. Thorax trapezoidal, schmäler als die Flügeldecken, mehr oder weniger gewölbt, mit ausgezogenen Ecken, glatt oder mit flachen Furchen und Grübchen versehen; die Mitte kann auch gefurcht sein. Schildchen breit. Flügeldecken zwischen den Schultern am breitesten, hinten schmäler werdend; ihre Oberfläche ist zumeist mit tiefen Punktreihen oder regelmässigen Furchen geziert; bei einer Art sind die Rippen durch seichte Punktreihen angedeutet. Pygidium stark gewölbt. Füsse ziemlich lang und schlank, die Vorderschienen mit zwei mehr oder weniger langen oder spitzen Zähnen bewehrt.)

Bates theilt die Strigoderma in

A. Arten mit 5 Streifen zwischen der Nath und den Schulterbuckeln.

B. " " 6

C. " " 7

D. " " 8

E. " " glatten, kaum angedeuteten Rippenstreifen.

I. Thorax glänzend, unbehaart, mehr oder weniger dicht punktirt, ohne Vertiefungen; alle Ränder mässig erhaben umsäumt, sehr fein punktirt.

Type: Strig. marginata Oliv.

1. Glänzend schwarz mit schwachem Erz- oder Kupferschimmer. Fühler mattschwarz. Thorax spärlich grob punktirt, ebenso das Schildchen. Flügeldecken glänzend gelb bis gelbbraun, schwarz umsäumt. Pygidium concentrisch gestrichelt und wie die Unterseite spärlich behaart. Schienen oben dick, stárk beborstet. Flügeldecken mit fünf Rippenstreifen.

Lănge 5-6 mm. Costa-Rica, Panama, Súdamerika, Antillen: marginata Oliv.

Olivier, Entomol. I, 5, pag. 3, Tf. 3, fig. 23.

2. Flïgeldecken flach und unregelmässig gefurcht, mit funf Rippenstreifen. Schmäler als die vorige Art, Kopf sperrig punktirt, Thorax an den Rändern dicht, oben spärlich punktirt. Flïgeldecken gelbbraun, 
die Nath, die Seitenränder und ein mehr oder weniger breiter Querstreifen in der Mitte schwarz.

Lănge 4-5 mm. Central- und Sitd-Amerika, Antillen:

marg. var. pygmaea Fabr.

Fabricius, Syst. Entom. Suppl. pag. 133.

2'. Grösser und breiter als pygmaea, dunkel erzgrun, Clypeus runzlich, erzgrün, bei $\odot$ gelblich. Fühler schwärzlich. Thorax in der Mitte grob zerstreut nunktirt, die Ränder dicht und fein; bei $ᄋ$ ist der Seitenrand gelbbraun gesäumt. Schildchen glatt, in der Mitte vertieft. Fluggeldecken bei $\sigma$ gelbbraun, schwarz gesäumt; bei ㅇ egal gelbbraun gefärbt. Pygidium fein gekörnt, anliegend greis behaart, bei 우 die Basis bräunlich. Füsse gelbbraun, Tarsen braun, behaart.

Lănge 5-7 mm. Panama, Columbien: columbica Burm. Burmeister, Handb. IV, 1, pag. 313.

3. Flügeldecken regelmässig gefurcht, Furchen tief, aus groben Punkten bestehend; mit sechs Rippenstreifen.

Type: Strig. festiva Bates.

$3^{\prime \prime}$. Schwärzlich grun, glänzend, lang gestreckt, ziemlich schmal. Kopf dicht punktirt, erzgrin, Fuhler schwärzlich. Thorax glänzend grün, gelbbraun gesäumt, hinten am erhabenen Rande jederseits ein sehr flacher Eindruck, der hintere Rand durch eine Furche abgesetzt. Schildchen zerstreut punktirt, eben. Flügeldecken glänzend gelbbraun, die Nath und Seitenränder dunkelbraun schmal umsäumt, die Randschwiele schmal, anfangs verdickt. Pygidium dunkelbraun, dicht chagrinirt, an der Basis schuitter greis behaart. Unten schwarzbraun, anliegend gelblich behaart; Beine rothbraun, metallisch glänzend; Tarsen dunkler, lang behaart.

Länge $6 \mathrm{~mm}$. Aus Mexiko:

orbicularis Burm.

Burm. I. c. IV, 2, pag. 515 .

3'. Wie die vorige Art gefürbt, nur der Thorax breiter, der Clypens scharf umrandet. Kopf erzgriun, körnig punktirt, Fühler schwarzbraun. Thorax grob gekörnt, der Randsaum gelbbraun gefärbt. Schildchen in der Mitte gefurcht, sonst zerstreut punktirt. Flügeldecken glänzend rothbraun, die Furchen aus ofters unterbrochenen Punktreihen bestehend. Randschwiele an der Basis verdickt, weiterhin glatt, schmal. Pygidium matt, fein gestrichelt, gelblich behaart. Beine glänzend rothbraun mit grünlichem Metallschimmer, die Tarsen dunkelbraun ohne Metallglanz, erstes Klauengied sehr gross.

Länge $6-7 \mathrm{~mm}$. Aus Mexiko:

festiva Bates.

Bates, Biol. Centr. Amer. Col., pag. 257. 
$3^{\prime \prime \prime}$. Der orbicularis ähnlich, nur der Thorax schmäler, und mit undeutlichem wulstigen Randsaume. Metallisch-grün glänzend, schütter behaart. Kopf dicht gekörnt, Scheitel fein punktirt; Füller schwarzbraun. Thorax in der Mitte zerstrent, an den Seiten dicht punktirt, sehr glänzend, der Seitensaum schmutzig gelb. Schildchen mit einigen Punkten geziert. Flügeldecken ziemlich flach, die Randschwiele scharf aufgeworfen; vor den Schulterbuckeln flach eingedrückt, glänzend fahlgelb, breit braun gesäumt. Pygidium dichtest gestrichelt, spärlich behaart, ebenso die Unterseite mit Einschluss der Beine.

Länge $8 \mathrm{~mm}$. Mexiko, Panama:

pallidipennis n. sp.

4. Flügeldecken wie bei der vorigen Gruppe, jedoch mit sieben Rippenstreifen.

Eine einzige Art: Strig. teapensis Bat.

4'. Oval, oben rothgelb, unten erzgrün, glänzend. Kopf sehr grob, Scheitel fein punktirt, Clypeus kurz, breit, Fühler schwarzbraun. Thorax erzgrin oder rothbraun, der Randsaum gelbbraun, am Innenrande schwärzlich, stark punktirt. Schildchen fast glatt. Flügelđecken glänzend gelbbraun, schwarz umsäumt, die Schulterbuckeln stark vortretend, verworren punktirt; die Randschwiele einfach. Pygidium bogig gestrichelt, rothgelb, spärlich behaart. Unterseite schwach behaart, Beine braun, erzgrün schimmernd, Hinterschienen kurz, stark grubig punktirt.

Länge $71 / 2-8 \mathrm{~mm}$. Aus Mexiko (Teapa): teapensis Bates. Bates 1. c. pag. 258, Tf. 14, fig. 17.

5. Flïgeldecken mit acht Rippenstreifen - sonst wie bei der vorigen Art.

\section{Type: Strig. costulipennis Bat.}

5 ". Länglich, schwärzlichgrün, glïnzend. Kopf egal grob punktirt, Clypeus klein, vorne schmäler, etwas geschweift, Fühler schwärzlich. Thorax dicht und feinst punktirt, die Basis stark geschweift, fein gelieit; Schildchen dicht punktirt, der Hinterrand glatt. Flügeldecken glänzend gelbbraun, die Randschwielc sowie ein konischer, die Nath einschliessender Längsstreifen schwarz. Die Rippen flach erhaben, die erste und zweite vor der Basis scharf aufgeworfen, die letzten geschweift; die Furchen selbst matt, ebenfalls seicht. Pygidium glänzend, fein punktirt. Unten bogig punktirt, greis behaart. Beine grün oder rothbraun mit Erzglanz, Tarsen dunkler gefärbt, beborstet.

Länge 6-7 mm. Aus Mexiko: costulipennis Bates. Bates 1. c. pag. 260, Tf. 14, fig. 2 . 
11". An die orbicularis erinnernd, nur ist hier der Thorax gröber punktirt, schütter gelblich behaart. Metallisch grün, glänzend. Kopf grob gekörnt. matt kupfrig schillernd; Clypeus fein chagrinirt, unbehaart; Fühler schwärzlich. Thorax fast quadratisch, sehr dicht gestrichelt, die Ränder gelblich behaart. Schildchen in der Mitte zerstreut punktirt, abrigens glatt. Flïgeldecken tief und breit gefurcht, glänzend gelbbraun, der Grund der Furchen fein punktirt, matt bräunlich, dic Nath breit, dunkelbraun. Pygidium convex, fein chagrinirt, lang greis behaart. Unten dicht bogig punktirt, lang behaart; Beine licht roth, sehr glänzend, Schienen mit Doppelquerreihen weisser Haare. Tarsen dunkelbraun, bewimport.

Länge 7-8 mm. Aus Mexiko: costulata n. sp.

II.

6. Thorax an den Rändern dicht und ziemlich grob, in der Mitte spärlicher punktirt, ohne den wulstigen Randsaum, nur fein gekielt, die Flügeldecken parallel tief gefurcht.

Type: Strig. Castor Newm.

6“". Oval, klein, erzgrün, glänzend. Kopf gekörnt, matt; Clypeus feiner chagrinirt, sein Vorderrand gelblich. Fühler braun. Thoraxränder grob grubig punktirt; glänzend grün, gelb gesäumt. Schildchen zerstrent grob punktirt. Flügeldecken fast parallel, breit, die Enden abgerundet, nicht schmäler werdend, die Randschwiele bei $\sigma$ an der Basis stark verdickt und geschweift - bei $Q$ blos schwielig, - gelbbraun, glänzend. schmal schwarz gerandet. Pygidium sehr glänzend, fein gestrichelt, greis behaart. Unten dicht bogig punktirt, die Beine braun, behaart, fein punktirt. Zahl der Rippenstreifen sechs.

Länge $61 / 2 \mathrm{~mm}$. Aus Mexiko:

physopleura Bates.

$6^{\prime \prime \prime}$. Oval, ziemlich flach, glïnzend rothbraun. Kopf dicht punktirt, matt blutroth, Clypeus feinst chagrinirt, unbehaart. Stirn dunkler gefärbt. Fühler dunkelbraun. Thorax dunkel ziegelroth, mit einer schwarzen spitzovalen Makel in der Mitte; sehr glänzend. Schildchen erzgrün, fein punktirt. Flügeldecken neben den Schulterbuckeln flach eingedrückt, der Grund der Furchen, aus groben queren Punkten gebildet, die Rippen hoch erlaben, glatt, die Randschwiele zur Mitte geschweift, überall egal glïnzend gelbbraun. Pygidium feinst chagrinirt, zerstrent behaart, dunkel ziegelroth; unten ebenso gefärbt mit Ausnahme der Brust, die fein gestrichelt, glänzend erzgrün ist. Beine glänzend rothbraun mit schwachem Erzsehimmer, Tarsen dunkelbraun, metallisch glänzend.

Länge $6 \mathrm{~mm}$. Panama, Chiriqui:

elegans 11. sp. 
6 "ü. Oval, länglich, licht kastanienbraun, glänzend, unbehaart. Kopf körnig punktirt, Scheitel dunkelbraun, Fühler schwärzlich. Thorax schmal, lang, oben flach gestrichelt, glänzend, in der Mitte eine längliche schwarzbraune Makel. Schildchen zerstrent punktirt, schwärzlich. Flügeldecken ziemlich flach, bei den Schultern eingedrückt, diese selbst erhaben, feinst punktirt. Pygidium und Unterseite schwärzlich, schwach glänzend, anliegend dicht greis behaart, spärlich punktirt. Füsse glänzend kastanienbraun, fein punktirt, sparsam behaart; Tarsen lang.

Länge $9 \mathrm{~mm}$. Aus Mexiko:

Bates 1. c. pag. 253 , Tf. 14 , fig. 10 .

longicollis Bates.

6". Glänzend schwarzgrün. Kopf fein punktirt, glänzend kupferbraun; Fühler schwärzlich. Thorax sehr glänzend, feinst punktirt, purpurfarbig. Schildchen metallisch grün, zerstrent punktirt. Flügeldecken glänzend schwarz, die Randschwiele mässig aufgeworfen. Pygidium schwärzlichgrün, sehr dicht punktirt, gelblich behaart, matt glänzend. Unten rothbraun, erzgrün schimmernd, Füsse braun, alles gelblich behaart.

Länge $61 / 2-7 \mathrm{~mm}$. Aus Mexiko, Guatemala: nigripennis Bates. Bates 1. c. pag. 257, 'Tf. 14, fig. 15 .

6'. Schwärzlich grün, kupfrig glänzend. Kopf kupferfarbig, egal fein punktirt; Fühler braun. Thorax gelb umsäumt, rosig schimmernd, sehr glänzend. Schildchen in der Mitte flach gefurcht, zerstreut punktirt, rosig angelaufen. Flügeldecken breit, flach, die Rippenstreifen hoch, die Randschwiele an der Basis stark verdickt und geschweift, entweder ganz gelbbraun - oder gelbbraun, mit einem schiefen aus schwarzen Flecken gebildeten Streifen in der Mitte. Pygidium fein gestrichelt, glänzend kupfrig, greis behaart. Unten dicht behaart, fein punktirt; Beine rothbraun, glänzend; Tarsen dunkelgrün, metallisch glänzend, schwarzbraun bewimpert. Vorderschienen zweizähnig, der zweite Zahn kanm sichtbar.

Var. 1. Kopf melır rosig-kupferfarben, Thorax überall feinst punktirt, ohne Metallglanz; Schildchen ohne Mittelfurche, Flügeldecken gleichmässig gelbbraun, nur die Nath und Randschwiele dunkelbraun (erstere schmal, letztere breit); Pygidium kupfrig braun mit Erzglanz; unten spärlicher behaart, - die Beine dunkler gefärbt (Castor Var. 1, Bates): . . . . . . . var. splendens n. v.

Länge 6-8 mm. Aus Mexiko, Nicaragua: Castor Newman. Newm., Trans. ent. Soc. III, 1841, pag. 49.

Bates 1. c. pag. 257. 
7. Thorax wie bei der vorigen Gruppe sculptirt, Flügeldecken mit sieben Rippenstreifen.

Type: Strig. tomentosa Bates.

14'. Schmal, äusserst glänzend, bronzegrün mit Kupfer- oder Erzschimmer. Kopf grob gerunzelt, Stirn glatt, glänzend - erzgrün oder kupferfarbig; Fühler schwarzgrün. Thorax wie der Kopf gefärbt, vorne schmal, mit je einem flachen Grübchen beim Seitenrande, die Basis gefurcht, oben entweder stärker aber schütterer (bronzefarbige Art) oder die Seiten dicht fein punktirt (erzgrüne Form); Schildchen im ersten Fall zerstreut punktirt, im letzten aber punktlos, sehr glänzend. Flügeldecken entweder fahlgelb, schwarzgrün umsüumt, dabei die Nath ebenfalls schwarzgrün - oder erzgrün, dunkler umrandet. Der erste Rippenstreifen neben der Nath stark vertieft. Pygidium convex, glatt. Unten sehr glänzend, metallisch grün oder kupferbraun, unbehaart, feinst punktirt. Füsse erzfarbig, kupfrig glinzend.

Länge 7-8 mm. Aus Mexiko und Honduras: lampra Bates. Bates 1. c. pag. 259, Tf. 14, fig. 19 und 20.

7‘. Oval, gelbbraun, seidenartig grünlich schimmernd. Kopf sehr dicht gekörnt, glänzend grün; Clypeus feiner chagrinirt, gelblich; Stirn stark punktirt, Fühler schwarzbraun. Thorax fast quadratisch, flach gewölbt, am Scheitel eine dreieckige dunkelgrüne Makel. Schildchen dicht punktirt, matt, dunkler gefärbt. Flügeldecken mit schmalen, mässig erhabenen Rippenstreifen, feiner Randschwiele, brauner Nath; Pygidium braunroth, fein chagrinirt, schütter behaart, grünlich schimmernd. Unten gleichartig gefärbt, dic Beine gelbbraun mit Erzschimmer, Tarsen dunkelgrün, braun bewimpert.

Länge 7-10 mm. Aus Mexiko:

tomentosa Bates.

Bates 1. c. pag. 258, Tf. 14, fig. 18.

7". Länglich, gewölbt, rothbraun mit grünem Metallschimmer. Kopf matt grün, glänzend, selır dicht punktirt, die Stirn dunkler, Fühler schwarzbraun. Thorax lang gestreckt, vorne schmäler, malachitgrün, die Seitenründer schmal gelbbraun gesäumt, an der Basis einige verwischte bräunliche Flecke. Schildchen grün, zerstreut punktirt. Flügeldecken glänzend schwarz, neben dem Schildchen je ein gelber Punkt, von den Schulterbuckeln zur Nath eine breite gewellte gelbe Binde. Die Randschwiele an der Basis lichtbraun, in der Mitte mässig geschweift. Pygidium und Unterseite dicht fein punktirt, schütter behaart; Beine metallisch grün, sehr glänzend, Schenkel gelbgestreift, Tarsen dunkelbraun mit Erzschimmer.

Länge $7 \mathrm{~mm}$. Aus Central-Honduras:

ornata n. sp. 
7“'. Der teapensis am nächsten verwandt, jedoeh breiter, mehr länglich-quadratisch. Schwarzbraun, glänzend. Kopf sehr fein gekörnt, Clypeus halbrund mit parallelen Răndern, die Stirn abstehend greis behaart. Fühler schwärzlich. Thorax stark gewölbt, fein punktirt, Schildchen etwas spärlicher. Flügeldecken licht schwarzbraun, der Seitenrand, die Endbuckeln und je ein Streifen neben der Nath schwarz, die Rippenstreifen schmal, aber hoch erhaben. Pygidium sehr glänzend, feinst zerstreut punktirt, abstehend greis behaart; ebenso ist die Unterseite mit Einschluss der Beine, wobei nur die Tarsen dunkler gefärbt erscheinen.

Länge $8 \mathrm{~mm}$. Aus Mexiko:

Bates 1. c. pag. 407.

III. Thorax überall gleichmässig dicht punktirt; theilweise oder gänzlich behaart.

\section{Type: Strig. mexicana.}

8. Die Flügeldecken regelmässig tief gefurcht, mit fünf Rippenstreifen.

8. Glänzend schwarz, erzschimmernd. Kopf dicht punktirt und behaart, Fühler schwarz. Thorax sehr dicht punktirt, Schildchen sperrig punktirt, unbehaart. Fligeldecken entweder 1) schaalgelb, die Schultern schwarz gesäumt - oder 2) ganz schwarz mit zwei gelben Punkten nahe am Rande - 3) gelbroth, der intermedia äbnlich, das Schildchen schwarz umsäumt, eine Querbinde in der Mitte, die Seitenränder und Schulterbuckeln ebenfalls schwarz 4) schaalgelb, die Nath an der Basis sebr breit, zuletzt schmal schwarz, die Seitenränder und Schultern wie bei 3) gezeichnet, nebstdem aber auch die Endbuckeln schwarz - endlich 5) ganz schwarz, erzschimmernd, nur neben der Nath an den Schulter- und oberhalb der Endbuckeln je ein gelber Fleck. Pygidium fein chagrinirt, behaart, ebenso die Unterseite.

Länge 7-8 mm. Aus Mexiko: mexicana Blanch. Blanchard, Cat. Coll. Ent. 1850, pag. 202.

9. Die Flügeldecken mit sechs Rippenstreifen.

Type: Strig. vestita Burm.

$9^{\prime}$. Länglich oval, bronzegrün, unten dichtest behaart. Kopf dicht punktirt, Scheitel fast glatt, Clypeus gelblich, matt. Fubler schwarzgrün, erstes Glied röthlich. Thorax länglich, oben nackt, die Ränder dicht grob punktirt, gelblich behaart - dunkel rothgelb mit Purpurschimmer. Schildehen glänzend grun, grob punktirt. Flügeldecken rothgelb, die Nath und die Randschwiele schwarz - oder 
gelbroth, die Rippenstreifen bräunlich. Letztere Exemplare waren sämtlich aus Guatemala. Pygidium grob chagrinirt, die Seiten lang gelblich behaart, die Mitte glatt. Füsse rothbraun, kupfrig glänzend, gelblich behaart; Tarsen dunkelgrün, metallisch glänzend, braun bewimpert.

Länge $6-\overline{\mathrm{mm}}$. Aus Mexiko und Guatemala: vestita Burm. Burm., Handb. IV, 1, pag. 314 .

9". Aehnlich der vorigen Art, haben aber ein anderes Haarkleid. Dunkel schwarzgrün, glänzend, sehr dicht behaart. Kopf mattt schwarz, sehr dicht gekörnt, schwach metallisch schimmernd. Fühler braunschwarz, erstes Glied röthlich. Thorax und Schildchen bronzegrün oder kupfrig, glänzend, sehr dicht punktirt, stark behaart, Haare lanzettförmig, gelbgrau. Flügeldecken rothgelb, sehr glänzend, mit brauner Nath und Randschwiele, die glatten Rippenstreifen hoch erhaben, breit. Schulterblätter fein punktirt. Pygidium und Unterseite fein punktirt, glänzend, schwärzlich, sehr dicht gelbgrau behaart. Beine rothbraun, kupfrig glänzend, weisslich behaart; Tarsen erzgrün.

Länge $6-8 \mathrm{~mm}$. Mexiko:

Salléi Bates.

Bates l. c. pag. 255, Tf. 14, fig. 9.

Anmerkung: Die in der Rothschild'schen Sammlung unter diesem Namen von Boucard bezeichneten Exemplare sind von den Bates'schen ganz verschieden und bilden eine neue Art (costulata mihi).

10. Mit sieben Rippenstreifen, sonst wie die vorige Art.

10. Oval, flach, glänzend purpurroth, dicht behaart, der lampra am nächsten stehend. Kopf dichtest gekörnt, einzeln behnart; Fühler braun. Thorax vorne schmäler, dic Basis stark geschweift, scharf gefurcht, Ränder dicht punktirt, fein lang behaart, Mitte glatt. Schildchen zerstreut punktirt. Flügeldecken glänzend gelbbraun, die Nath dunkel. Die Rippenstreifen breit, glänzend, die Randschwiele anfangs breit gefurcht - später einfach, schmal. Pygidium dicht punktirt, anliegend gelblich behaart, unten ebenso gefärbt, fein punktirt. Beine glänzend rothbraun mit rosa-kupfrigen Reflexen, spärlich behaart, die Tarsen dunkler gefärbt.

Länge 8-9 mm. Aus Mexiko: pilicollis n. sp.

Mit acht Rippenstreifen.

11. Glänzend bronzegrün, weisslich behaart. Kopf runzlich punktirt, matt schwarz, kupferschimmernd - auch grün, metallisch glänzend. Fübler schwarzbraun. Thorax vorne schmäler, dicht punktirt- 
gestrichelt, ein Streifen in der Mitte glatt, - uberall sonst sehr dicht weisslichgelb behaart. Schildchen an den Rändern grob punktirt, Mitte glatt. Flügeldecken gelb, die Seitenränder nebst der Nath dunkel - oder ganz schwarzbraun mit bronzegrüner Nath und Rändern - endlich aber ganz dunkelgrün. Pygidium rothbraun mit Erzschimmer, an der Basis sehr dicht, sonst spärlich behaart. Unterseite bogig punktirt, schutterer behaart. Beine kräftig, metallischgrün; Tarsen dunkelgrün, braun bewimpert.

Länge 9-11 mm. Aus Mexiko:

hirsuta n. sp.

IV. Thorax sehr fein punktirt, in der Mitte gefurcht; Fluggeldecken ohne Rippenstreifen, diese durch sehr feine Punktreihen nur angedeutet.

12. Länglich oval, sehr glänzend. Kopf fein punktirt, blau, Scheitel glatt; Fühler schwärzlichblau. Clypeus trapezoidal, vorne fein ausgebuchtet. Thorax blau, zerstreut punktirt, beiderseits mit je drei flachen Strichen. Schildehen zerstreut punktirt, Flugeldecken glänzend schwarz, Pygidium und Unterseite fein punktirt, glänzend goldgrün. Beine blau, Schenkel dagegen goldigroth oder goldgelb gefärbt.

Länge $14 \mathrm{~mm}$. Aus Nicaragua: Bates l. c. pag. 260 , Tf. 14 , fig. 22.

auriventris Bates.

13. Thorax bei den Rändern flach eingedrückt, der Rand mehr oder weniger erhaben (wulstig); die Fligeldecken tief parallel gefurcht.

Type: Strig. heraldica.

13. Mit sieben Rippenstreifen.

13 “. Oval, flach, dunkel bronzefarbig, glänzend, weisslich behaart. Kopf grob punktirt, glänzend grun; Clypeus chagrinirt, vorne braunroth, erzschimmernd. Fühler schwarzbrann. Thorax breit, vorne fast gerade, hinten dagegen mässig geschweift, runzlich, an den Seiten dichter punktirt, dort auch flach eingedrückt; glänzend grün, gelb gesäumt. Schildchen zerstreut punktirt. Flingeldecken tief gefurcht, die Furchen aus groben losen Punkten bestehend, die Rippenstreifen hoch. glatt; die Randschwicle an der Basis sehr breit, stark verdickt, späterhin schmäler werdend. Farbe: egal braunroth, nur die Ränder des Schildchens und eine ovale Makel am Endbuckel gelb (Thorax hier kupfrig schimmernd) oder licht gelbbraun, der Randsaum in der Mitte bis zur Nath reichend (Thorax rein grün ohne Kupferglanz). Pygidium erzgrän, anliegend greis behaart, dicht gestrichelt. Füsse erzgrün, kupfrig schimmernd.

Länge 7-8 mm. Aus Mexiko:

Rothschildi n. sp. $19 *$ 
Mit sechs Rippenstreifen.

13'. Breit, oval, dunkelrothbraun, sehr glänzend. Kopf sehr dicht punktirt, kupfrig, am Scheitel erzgrun schimmernd. Clypeus fein chagrinirt, matt; Fühler schwarzbraun mit schwachem Metallglanz. Thorax flach gewölbt, die Ränder grob und dicht, die Mitte dagegen zerstreut punktirt; erzgrün schimmernd, gelbbraun gesäumt, die Mitte mit einer braunen einer heraldischen Lilie ähnlichen Makel geziert; nebstdem je ein kleiner flacher brauner Punkt dicht am Seitenrande. Schildchen metallisch glänzend, die Mitte gefurcht, sonst zerstreut punktirt. Flugeldecken flach gestreift, die Furchen aus groben flachen Punkten gebildet, um das Schildchen erhaben, $z$ wischen der Nath und den Buckeln der Länge nach flach vertieft; die Randschwiele breit gefurcht, in der Mitte verdickt und geschweift. Farbe glänzend rothbraun, der erste Rippenstreifen fast ganz, der zweite bis vierte immer kürzer gelb gefärbt. Pygidium conisch, chagrinirt, matt, an der Basis sehr dicht, weiter weniger anliegend goldgelb behaart. Bauchsegmente kupfrig, die Unterseite erzgrün, flach punktirt, zerstreut goldgelb behaart. Schienenenden gerunzelt und wie die Tarsen dunkler gefärbt.

Länge 11-12 $\mathrm{mm}$.

heraldican. sp.

V. Thorax leicht gewölbt, zerstreut punktirt, unbehaart, mit flachen Grubchen nahe der Seitenränder. Flügeldecken mit starken Furchen, der erste eventuell bis vierte und sechste Rippenstreifen hoch erhaben.

\section{Type: Strig. lampra Bat.}

$14^{\prime \prime}$. Länglich oval, licht rotbbraun, sehr stark gelbgrün glänzend. Kopf dicht gekörnt, matt rothgoldig; Fühler nussbraun. Thorax mit fein gekielten Seitenrändern, sehr glänzend. Schildchen zerstreut punktirt. Flügeldecken flach, hinten bogig gerundet, die Nath stark stark erhaben; die Randschwiele schmal, mässig verdickt; der erste bis vierte, dann der sechste Rippenstreifen hoch erhaben, der Furchengrund aus unregelmässigen Punkten bestehend, der der fünften Furche oben und unten gespalten; wie der Thorax gefärbt, neben den Schildchen beiderseits je eine lichtere nierenförmige Makel. Pygidium sehr dicht bogig gestrichelt, unbehaart. Unten spärlich greis behaart. Schenkel licht gelbgrün, Schienen rothbraun, ihre Enden kupfrig angelaufen, Tarsen glänzend rothbraun; Vorderschienen mit zwei Zähnen bewehrt, der zweite weit vom ersten gestellt.

Länge $8 \mathrm{~mm}$. Aus Central-Honduras: micans n. sp. 
VI. Thorax trapezoidal, vorne gebogen, hinten parallel, glatt, oder spärlich behaart, die Mitte gefurcht, an den Seiten flache eingedrückte Streifen.

Type: Strig. sulcipennis.

15. Mit fünf seichten, flachen Rippenstreifen; schwarz, glänzend, schwach erzschimmernd. Kopf dicht, Scheitel sperrig punktirt, Fühler schwärzlich. Thorax sehr dicht punktirt, schwach behaart, erzgrün; Schildchen dicht punktirt. Flügeldecken mit stark erhabenen Rippenstreifen, in der Färbung der intermedia oder mexicana var. b) ahnlich (schwarz, mit gelben Randstreifen, oder mit gelben Querbinden). Pygidium fein chagrinirt, schütter behaart, ebenso die ganze Unterseite mit Einschluss der Beine.

Länge $6 \mathrm{~mm}$. Aus Mexiko:

protea Chevrolat.

Dej. Cat. 3. ed., pag. 175.

16". Mit sechs Rippenstreifen, Glänzend schwarzgrün. Kopf tief grubig punktirt, Fühler schwärzlich. Thorax schmal, tief punktirt, beiderseits mit drei schiefen eingedrückten Streifen, glänzend rothbraun oder schwarz, ebenso das Schildchen gefärbt, das aber zerstreut punktirt ist. Flügeldecken wie der Thorax gefürbt, kupfrig schimmernd, bei den Schulterbuckeln flach eingediückt, tief gefurcht, der erste bis achte Rippenstreifen hoch gewölbt, der neunte flach; bei 우 die Randschwiele in der Mitte geschweift und verdickt. Pygidium fein chagrinirt, matt, greis behaart. Unten rothbraun oder schwarzgrün, glänzend, schütter behaart.

Lănge $6-61 / 2 \mathrm{~mm}$. Mexiko, Guatemala: contracta Bates. Bates 1. c. pag. 253, Tf. 14, fig. 11 .

16. Oval, vorne schmäler, glänzend grün. Kopf sehr dicht punktirt, Fühler schwarzgrün. Thorax egal dicht punktirt, beiderseits beim Seitenrande je eine flache Makel - metallisch grïin, gelb umsäumt. Schildchen zerstreut punktirt, bräunlich mit Kupferglanz. Flügeldecken bei $\sigma^{\top}$ gelb, breit schwarz gesäumt, ein schwarzer Flecken beiderseits des Schildchens, ferner sind die Schulter- und Endbuckeln nebst der Nath schwarz. Das $Q$ e einfarbig gelbbraun. Die Randschwiele breit, verdickt, die Rippenstreifen hoch, gleich gerundet. Pygidium fein spärlich gestrichelt, schütter behaart, schwärzlich. Unten mit Einschluss der Beine glänzend grü, fein punktirt und behaart.

Länge 6-9 $\mathrm{mm}$. Nicaragua, Costa-Rica, Panama:

rutelina Bates.

Bates l. c. pag. 258, Tf. 14, fig. 16. 
Eine interessante Varietät stammt aus Nicaragua (Bates Var. 1):

Ganz gelbbraun, glänzend, nur der Thorax dunkelgrïn, gelbbraun gesäumt, in der Mitte ein flacher Längsstreifen - die übrigen Eindrücke wie bei der vorigen Art (var. testacea mihi).

16“. Sehr länglich, elliptisch, schlank, glänzend schwarzviolett, in der Farbe am meisten variirend; Flügeldecken mit acht Rippenstreifen. Kopf gekörnt, um die Augen borstig; Fühler stets matt schwarz. Thorax in der Mitte tief gefurcht, an den Seitenrändern je drei schiefe Furchen. Schildchen glänzend blauschwarz, seltener grünlich, dicht punktirt. Flügeldecken mit breiten, abgerundeten Rippenstreifen, der Grund der Furchen quer punktirt. Pygidium concentrisch gestrichelt, leicht behaart. Unten glänzend, fein punktirt, graugelb behaart. Füsse glänzend schwarzblau oder grünlich, die Schenkel meist hellgelb, Vorderschienen zahnlos.

Länge 7-15 mm. Aus Mexiko, Guatemala, Honduras, Nicaragua.

Stammart: Flügeldecken gelbbraun, die Rippen braun oder schwarzbraun; Kopf, Thorax nebst Unterseite schwarzblau.

Burm. Handb. IV, 1, pag. 316.

sulcipennis Burm.

Var. 1. Kopf, Thorax und Unterseite violettschwarz, Flügeldecken mit dichten tiefschwarzen Rippenstreifen, Beine schwarz, Schenkel auch gelb gefleckt: var. nigripes Dej.

Burm. 1. c. pag. 316 .

Var. 2. Wie die vorige Art, nur sind die Flügeldecken rothgelb, während die Tarsen schwarz oder auch rothbraun sind:

Burm. l. c. pag. 316.

var. fastuosa Klug in litt.

Var. 3. Kopf und Thorax ganz oder breit purpurgoldig gesäumt, Flügeldecken egal rothgelb, Unterseite violettschwarz mit schwarzen oder rothbraunen Tarsen: var. trochilus Sturm.

Sturm Cat. 1843, pag. 121.

Var. 4. Kopf und Thorax goldgrün, unbehaart, röthlich schimmernd, letzterer fast ohne Punkte; Schildchen schwärzlichgrün, Flügeldecken dicht gefurcht, tief rothbraun; unten schwarzbraun, erzschimmerud, Hinterschenkel goldgrün.

Aus Guatemala:

var. metallica n. v.

Var. 5. Schlanker und flacher als sulcipennis; Kopf dunkelpurpur, dicht grob punktirt; Clypeus erzgrün. Fühler schwarz. Thorax glänzend grün mit Purpurschimmer, mit zwei flachen Seitenfurchen, tiefer Mittelfurche, die an der Basis sich rundlich erweitert. Schildchen 
schwarzgrün. Flügeldecken gelbbraun, die Nath und die Randstreifen dunkelbraun. Unten schwarzgrün, fein gestrichelt, Beine lichter, Schenkel gelb, Tarsen dunkelbraun.

Länge $10 \mathrm{~mm}$. Aus Mexiko:

var. impressicollis n. v.

Var. 6. Schwarz, ohne Metallschimmer, glänzend. Kopf dicht punktirt, Clypeus schwach kupferglänzend. Thorax egal schwarz, mit einzelnen Härchen. Schildchen spärlich punktirt, erzgrün. Flügeldecken gelbbraun, fein und tief gefurcht, Nath braun. Pygidium rothbraun, chagrinirt. Unten flach punktirt; Beine rothbraun, erzschimmernd, die Tarsen braun. Ahmt die Strig. arboricola nach.

Länge 10-12 mm. Aus West-Mexiko: var. immitatrix n. v.

17. Schwarz, glänzend, schwach grünlich schimmernd. Kopf grob gekörnt, einzeln gelblich behaart, Stirn schwach kupfrig, Fühler matt schwarz. Thorax feinst punktirt, spärlich behaart, mit einem flachen Mittelstreifen und zwei länglichen Grübchen neben dem Seitenrande schwarzgrün, purpurschimmernd. Schildchen erzgrün, zerstreut grob punktirt. Flügeldecken fahlgelb, g]änzend, wie bei arboricola sculptirt, mit brauner Nath und Randschwiele; die Rippen nicht wie bei der obenerwähnten Art braun, sondern ebenfalls einfarbig fahlgelb. Pygidium erzfarben, fein chagrinirt, glänzend, zerstreut behaart (im Gegensatze von arboricola, wo es fein runzlig, weich grau behaart ist). Beine ziemlich lang, Schenkel und Schienen olivgrtin, Tarsen glänzend braunschwarz.

Länge 9-10 mm. Indianer-Reservations: arboricola var. testaceipennis n. v.

Diese interessante Varietät, obzwar dicht von der Nordgrenze Mexiko's stammend, gehört zwar in die Fauna Nordamerika's; der Umstand jedoch, dass sie weiter suddich in der subtropischen Region verbreitet sein könnte, hat mich bestimmt, sie hieher aufzunehmen.

17'. Glänzend sehwarz. Kopf dicht grob punktirt, Fühler schwarz. Thorax in der Mitte sperrig, an den Seiten dichter punktirt, in der Mitte drei flache Längsfurchen, beiderseits am Rande eine solche Makel; die erhabenen Ränder dieser Furchen und Makeln feinst punktirt, ebenso das Schildchen. Flügeldecken flach punktirt-gestreift, schwarz mit zwei breiten hellgelbbraunen Querbinden, die erste in der Mitte, die zweite dicht unter ihr (nebstdem ist die erste Binde durch einen bis zur Basis reichenden Längsstreifen unterbrochen). Die Nath vom Schildehen an schwarz - vom Unterrande der gelben Querbinde anfangend gelbbraun. Unterseite spärlich behaart, schwach metallisch glänzend. 
Läge 5-7 mm. Aus Mexiko, Guatemala, Brit. Honduras: intermedia Bates. Bates 1. c. pag. 253 , Tf. 14, fig. 8 .

Nachträglich sind mir noch folgende 3 Spezies bekannt geworden:

14'. Langgestreckt, goldgrün, röthlich glänzend. Kopf klein, dicht, Stirn spärlicher punktirt. Olypeus chagrinirt, Fühler rothbraun. Thorax in der Mitte breiter, eine flache Vertiefung bei den Vorderecken, nahe der Seitenränder je ein Grübchen. Schildchen zerstreut grob punktirt. Flügeldecken rothbraun, die Nath grün schimmernd; mit 13 parallelen, seichten, feinen Punktreihen, einfacher glatter Randschwiele. Pygidium röthlich, erzschimmernd, fein chagrinirt, gelblich behaart. Beine gelbgrün, kupfrig glänzend; Tarsen rothbraun, glänzend.

Länge $10 \mathrm{~mm}$. Aus Chiriqui:

gracilis n. sp.

14“". Glänzend bronzegrän, mit röthlichen Reflexen. Kopf egal dicht punktirt, glänzend grün. Clypeus bräunlich, unbehaart; Fühler lehmgelb, der Fühlerfächer braun. Thorax flach gewölbt, nadelrissig gestrichelt, am Seitenrande je ein flaches Grübchen; unbehaart. Schildchen zerstreut punktirt. Flügeldecken länglich, gewölbt, breit gefurcht, der Furchengrund grob quer punktirt, der zweite Rippeustreifen breit, verworren punlitirt; auch um das Schildchen zerstreat grob punktirt. Pygidium dicht chagrinirt, spärlich behaart. Unten bogig punktirt, sehr spärlich behaart. Beine zierlich, Tarsen glänzend braun.

Länge $8-10 \mathrm{~mm}$. Aus Mexiko:

subaenea n. sp.

Var. 1. Der vorigen Art ähnlich, äberall weisslich behaart. Kopf matt schwarz mit Kupferschimmer, runzlig punktirt (bei einem Exemplar auch metallisch-grün gefärbt). Fühler rothbraun. Thorax mit einem flachen glatten Mittelstreifen, ziemlich glänzend, sehr dicht behaart. Schildchen rothbraun, erzglänzend, dicht grob punktirt. Flügeldecken schwarz mit grünen Reflexen, matt glänzend. Pygidium nadelrissig sculptirt; rothbraun, erzgrün glänzend, der Rand spärlich behaart. Unten rothbraun, ohne Metallglanz, flach punktirt, Tarsen dunkler gefärbt.

Länge 8-10 mm. Aus Mexiko (Cuera):

subaenea var. Jordani n. v. 